\title{
Renewable Energy Support Mechanisms — Present Status
}

\author{
F. Martins, C. Felgueiras, and M. Smitková
}

\begin{abstract}
Renewable energy production is important to solve problems related to security of supply, economic competitiveness, reduction of the economic energy burden to citizens and environmental impacts such as $\mathrm{CO}_{2}$ emissions and pollution. Besides this the scenarios for the future foresee an increase in energy demand mainly due emerging economies and by this reason all the above mentioned issues will be crucial for EU Member States and many other countries around the world. Due to the inability of market to move to more sustainable energy systems, using a higher share of energy from renewable energy sources, it was necessary public action, creating RES support mechanisms in the majority of countries.
\end{abstract}

Index Terms-Energy, RES, support mechanisms.

\section{INTRODUCTION}

Renewable energy is nowadays important worldwide since many human activities are increasingly related to energy consumption. Development of countries and economies are intrinsically related to energy and energy resources. To have energy resources does not imply a social and economic improvement of countries; nevertheless it is an important and necessary condition to strength and to maintain competitiveness of economies and to promote social improvements. European Union (EU) for example due to its high external energy dependency has changed its energy policy and renewable energy sources (RES) are seen as a key factor to overcome or at least to decrease this vulnerability [1]. Environmental aspects such as global warming are also forcing countries towards to more low carbon energy systems. International agreements and commitments such as the Kyoto protocol and pos-Kyoto agreements are also important drivers in this context.

In EU the RES Directive 2009/28/EC has established targets to the share of RES in final energy consumption, namely $20 \%$ by 2020 , and a minimum of $10 \%$ for renewable energy in the transport sector [2].

Energy policies and pathways to achieve more sustainable energy systems are being planned in many countries of the world, in Europe, Asia, America, etc. Besides according to International Energy Agency (IEA) global energy demand will grow by $37 \%$ by 2040 in its central scenario and the distribution of energy demand will radically change with raising consumption in countries such as China, India and in the Middle East [3]. However even the developing countries, which are presenting a rapid consumption growth in all energy sectors, will have also to address energy security and

Manuscript received March 20, 2015; revised July 17, 2015.

F. Martins and C. Felgueiras are with the Instituto Superior de Engenharia do Porto (ISEP), School of Engineering, Polytechnic Institute of Porto (IPP), Porto, Portugal (e-mail: $\{\mathrm{ffm}, \mathrm{mcf}\} @$ isep.ipp.pt).

M. Smitková is with the University in Bratislava, Slovakia (e-mail: miroslava.smitkova@stuba.sk).
$\mathrm{CO}_{2}$ emission reduction policies. For those countries RES is also an issue of great importance to their development.

The perception of these problems lead to new energy policies and support schemes to finance RES since the market does not assure the necessary level of renewable without public action.

This is mainly due to fossil fuel subsidies, weak internalization of external costs such as air pollution, energy security and the low flexible system design which causes market and regulatory failures [4].

So to enhance the development of renewable energy technologies and to promote the integration of renewable energy in the systems many countries had to implement support mechanisms.

However if market regulations are not well designed this can lead to excessive profits in renewable sector, increasing policy costs, and the active seek for rents [5].

The implementation of support mechanism is for the above mentioned reasons an iterative process and should be analyzed and revised periodically to adjust to the several factors such as technology development, technology maturity, market conditions, etc.

\section{SUPPORT MECHANISMS}

Several instruments can be used to support RES namely feed-in tariffs, feed-in premiums, quota obligations, tax exemptions and investment grants.

A feed-in tariff is a fixed and guaranteed price set by government to be paid to producers of electricity from renewable sources, assuming total coverage. In feed-in premium part of revenue comes from the electricity sold on the market and part is a guaranteed premium, so there is partial support coverage. In quota obligation a market is created for the electricity from renewable sources. Government imposes an obligation on consumers or suppliers to source a given amount of electricity from renewable sources.

The support schemes can be based on price or quantity targets. Feed-in tariffs and feed-in premium are price- based schemes while quota obligations are volume-based ones.

To calculate the required support level several approaches can be used such as cost-based, avoided $\mathrm{CO}_{2}$ emissions, avoided health damage from avoided pollution, avoided final energy or fossil fuel imports and energy security [6].

The European Comission (EC) considers the cost-based approach, namely the levelised cost of electricity (LCOE) as best practice. One important advantage of this method is to make systems more comparable [4]. The other approaches rely on estimations and to not reflect the cost of energy production [6].

The support level is then determined according to LCOE and is carried out in three steps, namely costs, revenues projections and LCOE translation to support scheme [6]. The 
support will cover the gap between costs and revenues, providing a suitable level of profitability. The third step can be very complex especially in the cases where part of the revenue come from the market.

When auctions are used they represent a way of allocating financial support and can be used to determine the level of support based on the bidders offers' cost estimations.

Support schemes can be technology neutral or technology specific. Differentiated support has as main the advantage the development and implementation of less mature and expensive technology however it can lead to windfall profits [6].

Due to its traditional characteristics, providing a long-term fixed level of support which lowered the risks feed-in tariffs were very important because they allow to achieve high deployment of RES. The main disadvantage was that they are not very compatible with market. They can provide differential support according to the level of development of technologies however given the guaranteed price it does not promote the reduction of costs. On the hand quota obligation due its orientation to the market induces the seek for cost reductions however usually they are technology neutral which means that will not contribute as actively for the deployment of less mature technologies.

To implement these support instruments it is necessary funding that usually comes from a public budget or by consumers (levy linked to the level of consumption). Since it is important to maintain public acceptance of RES support it is crucial not to create excessive burdens and to make a fair distribution of costs. That is why rents should be controlled. Tax exemptions are another issue that should be controlled since granting exemptions or reducing levy to some increases the burden to the remaining electricity consumers.

For developing countries several international mechanisms were proposed to support feed-in tariffs. The ten main proposals for supported feed-in tariffs were identified and classified into three categories: globally managed feed-in tariffs, domestically managed supported feed-in tariffs and globally managed incremental feed-in tariffs. Other alternatives have been explored to support renewable energy in developing countries [7].

Another aspect to consider is RES integration and that is linked to the type of support instrument used. Demand oriented production should be implemented to avoid negative prices so support instruments linked to market maybe more compatible with this. System stability is another major aspect to consider and this can be achieved by balancing responsibility between operators including plant operators, remote control and dispatch and provision of system services. [6] EC proposes a set of best practices to minimize impacts on power markets that recommend for example the application of network codes (gate closure, balancing obligations, etc.) which do not discriminate power producers [4]. Other analysis is made concerning policies to integrate renewable energy [8].

\section{SUPPORT MEChANISMS - PRESENT SitUATION}

\section{A. $E U$}

The deployment of some RES technologies such as PV associated with the economic crisis lead to the increase of costs related to RES. Due to that some EU Member States had to implement measures to control policy costs.

In order to achieve this goal several options are being considered, depending of the type of support instrument used. For volume-based instruments such as quota obligation or auctions/tenders policy costs are usually controlled by the establishment of targets. In feed-in systems that are price-based instruments degression (fixed degression rates, degression after periodic review and capacity dependent degression) is an important measure to control policy costs. Other important aspects in this matter are the time horizon and the technology level [6]. Table I presents the support instruments for EU Member States in 2013 (data from [4]).

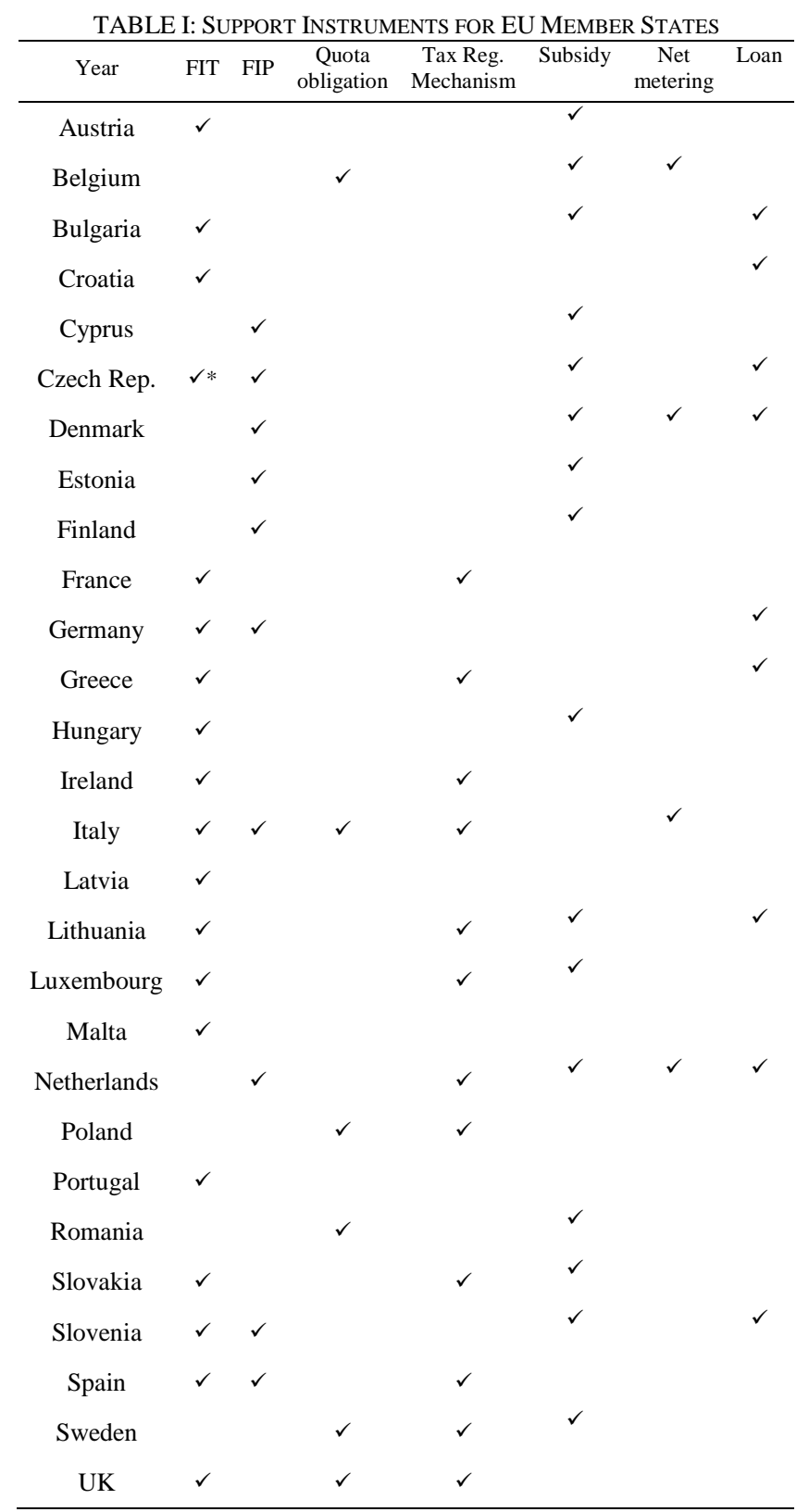

*The Czech republic has legislation to remove feed-in tariff support for all RES technologies as of January 2014

Feed-in tariff still is one of the most common instruments of support in EU. Only 4 countries in EU do not have feed-in systems, namely Bulgaria, Poland, Romania and Sweden that have implemented quota obligation.

Nowadays however the support instruments are not so clearly distinguishable due to modifications implemented to 
adjust to changes. Cap and floor prices have been considered in quota obligation and volume caps have been introduced in feed-in systems [6].

In the majority of Member States the financing is off budget which means that electricity consumers have the burden of financing renewable energy. Only in two countries namely Luxembourg and Netherlands the financing comes from budget. In Belgium there is an hybrid system [4].

Net-metering is a measure introduced worldwide and allows consumers to offset part or all of their electricity consumption with self produced electricity from RES-E systems [9]. In 2013 four EU countries used net-metering namely Belgium, Denmark, Italy and Netherlands [4]. In 2014 that number raised to 9 countries [10].

Renewable energy policies are still growing in World. In 2013 according to Global Status Report 2013 there were being implemented in 127 and by early 2014 that number raised to 138 . In spite of this growth is noticeable a slow down since many countries have already renewable energy policies [10]. In the beginning the implementation of renewable energy policies were performed mainly by developed countries, which are now in a process of reviewing those measures but developing and emerging countries have led in recent years [10].

\section{B. High Income Countries}

This group is mainly constituted by European countries such as EU Member States, Switzerland, Norway, North America countries such as Canada and United States, some Asian countries such as Japan and Russia. In what concerns high income countries all of them have renewable energy targets with the exception of Andorra and Singapore. Feed-in systems are also very common since 27 countries out of 43 have this kind of support instrument, corresponding to $63 \%$. In what concerns quota obligation it is present in 16 countries and only 9 countries do not implemented either a feed-in system or a quota obligation. In 17 countries was implemented net-metering but 9 of these countries belong to EU. 21 countries have implemented tendering with 11 countries from EU. In what concerns fiscal incentives and public financing that includes capital subsidy or rebate, investment or production tax credits, reduction in sales, energy, $\mathrm{CO} 2$, VAT or other taxes, energy production payment and public investment, loans or grants only a very small percentage of countries don't have this kind of measure, around 5\% (data from [10]).

\section{Upper-Middle Income Countries}

This group is constituted by 41 countries, including 3 EU Member States namely Bulgaria, Hungary and Romania, African countries such as Angola and South Africa, some BRIC countries such as Brazil and China, Turkey, Iran, Mexico among others. In what concerns upper-middle income countries all of them have renewable energy targets with the exception of Angola, Bahrain, Belarus, Ecuador, Iran, Panama and Peru In this group feed-in systems are still very implemented since 20 countries out of the 41 have this kind of support instrument. In what concerns quota obligation it is present in 6 countries and roughly half of the countries do not implemented either a feed-in system or a quota obligation (18). Comparing with high income countries the percentage is 23 percentage points lower. Only 13 countries has implemented net-metering with 1 country belonging to EU, which means that this measure is being more implemented in high income countries but the difference is percentage points is not very big ( around 8) which means this measure is being adopted around the world. 18 countries have implemented tendering corresponding to a percentage of $44 \%$ which is identical to the percentage obtained for high income countries $(48 \%)$. In what concerns fiscal incentives and public financing all of them have some kind of measure that falls into this category (data from [10]).

\section{Lower-Middle Income Countries}

This group is constituted by countries such as Armenia, Egypt, India, Indonesia, Morocco, Nigeria, Sri Lanka, Syria, Ukraine, and Vietnam. In this group most of them have renewable energy targets with the exception of Armenia, Cameroon, El Salvador, Paraguay and Uzbekistan. Feed-in systems are also very common since 15 countries out of 30 have this kind of support instrument. In what concerns quota obligation it was adopted in 6 countries and 13 countries do not implemented either a feed-in system or a quota obligation. The percentage obtained in this group is similar to the one obtained for upper-middle income countries. In 13 countries was implemented net-metering which corresponds to a percentage of $43 \%$, which is higher than the ones obtained for the 2 other groups. Concerning tendering the percentage is similar to the other two groups. In what concerns fiscal incentives and public financing around $13 \%$ of the countries don't have this kind of measure (RES21 2014).

\section{E. Low Income Countries}

This group is constituted by poor countries such as Bangladesh, Ethiopia, Guinea, Malawi, Mozambique, Uganda, etc. In this group there are 7 countries with no renewable energy targets out of a total of 24. Very few countries have feed-in systems. Only 5 countries have implemented this support instrument. In what concerns quota obligation it was adopted in 1 country and the majority of countries do not implemented either a feed-in system or a quota obligation (18). Net metering was not implemented in any country and tendering only is present in 3 countries. In what concerns fiscal incentives and public financing only a very small percentage of countries don't have this kind of measure, around $8 \%$. The most implemented measure in this category is reduction in sales, energy, $\mathrm{CO}_{2}$, VAT or other taxes. This measure is also present in all the other groups with a high percentage, respectively $65 \%, 59 \%$ and $67 \%$ but in this group it presents the highest value with $79 \%$ (data from [10]).

\section{F. Overall Analysis}

Feed-in tariff under other name was first introduced by United States in 1978 and then followed by European countries in 1990s. When comparing the evolution of RES support instruments from to 2005 to 2014 it is possible to conclude that there was a clear evolution that was first led by developed countries and that is now disseminated worldwide as presented in Table II (data from [10]-[12]).

Global new investment has decreased since 2011 to 2013. The reasons for this are the uncertainty related to policy support and reductions in technology costs. In fact concerns about future policy support are holding back investors in many EU countries and also in United States. Many UE 
countries and other countries have implemented changes in their support mechanisms and some of them such as Spain wanted to implement retroactive reductions in support.

In 2013 China alone invested more in renewable energy than all the European countries (data from [10]).

Another issue in discussion is own-consumption and net-metering. This measure can help to adjust consumption to generation to reduce grid load, leading to a more distributed generation model and reducing the investment needed.

By 2013 more than 3 million EU households produced their own electricity [10]. This may lead to a problem: to know who will pay the costs of grid connection and provision necessary to assure security of supply. In the case of deployment of distributed generation the system costs may be distributed by only a small number of consumers.

According to stakeholders it will be necessary a new model's business for the energy sector moving from a volume-based supply model to a service-based model [10].

TABLE II: RES POLICIES AND TARGETS WORLDWIDE

\begin{tabular}{|c|c|c|}
\hline Year & RES promotion policies & $\begin{array}{c}\text { Policy targets for renewable } \\
\text { energy }\end{array}$ \\
\hline 2005 & $\begin{array}{c}48 \\
34 \text { developed and transition countries } \\
14 \text { developing countries }\end{array}$ & 45 (all 25 EU countries) \\
\hline 2010 & $\begin{array}{c}83 \\
41 \text { developed and transition countries } \\
42 \text { developing countries }\end{array}$ & 85 (all 27 EU countries) \\
\hline 2014 & $\begin{array}{c}138 \\
95 \text { developing and emerging economies }\end{array}$ & 144 (all 28 EU countries) \\
\hline
\end{tabular}

\section{CONCLUSIONS}

Renewable energy sources are the pathway chosen for the majority of countries to face present and future challenges. Security of supply and reduction of $\mathrm{CO}_{2}$ emissions and pollution are among the most important concerns. In order to promote renewable energy countries had to change their energy policies and establish targets for renewable energy. Support instruments were fundament to deployment of RES since the market alone was not able to do the necessary investments.

This strategy began with developed countries but in about 15-20 years was implemented in 144 countries, including developing and emerging economies. This strategy has different patterns that adjust to the countries characteristics and the support instruments adopted and implemented in each country translate that diversity. However when analyzing the support instruments implemented it is possible to verify that feed- in systems are of the most adopted instrument.

Past experience in Europe and other regions had shown that they were very important to promote RES energy generation but they should be revised periodically and adjusted to current conditions. The link between support instruments and market is also very important to avoid excessive costs and windfall profits. New measures such as net-metering are being implemented and this may lead to a new business model for energy production sector.

\section{REFERENCES}

[1] European Commsission, "Energy challenges and policy," 2013.

[2] Directive 2009/28/EC of the European Parliament and of the Council of 23 April 2009.

[3] IEA, "World energy outlook 2014 - executive summary," 2014.

[4] European Commission, "European commission guidance for the design of renewable support schemes," 2013.

[5] T. Know, "Rent and rent-seeking in renewable energy support policies: Fee-in tariffs vs. renewable portfolio standard," Renewable and Sustainable Energy Reviews, vol. 44, pp. 676-681, 2015.

[6] Ecofys, "Design features of support schemes for renewable electricity," 2013.

[7] J. Huenteler, "International support for feed-in tariffs in developing countries - A review and analysis of proposed mechanisms," Renewable and Sustainable Energy Reviews, vol. 39, pp. 857-873, 2014.

[8] Z. Abdmouleh, R. A. M. Alammari, and A. Gasti, "Review of policies encouraging renewable energy integration \& best practices," Renewable and Sustainable Energy Reviews, vol. 45, pp. 249-262, 2015.

[9] A. Poullikkas, G. Kourtis, and I. Hadjipaschalis, "A review of net metering mechanism for electricity renewable sources," International Journal of Energy and Environment, vol. 4, issue 6, pp. 975-1002, 2013.

[10] REN21, "Renewables 2014 global status report," 2014.

[11] REN21, "Renewables 2010 global status report," 2010.

[12] REN21, "Renewables 2005 global status report," 2005.

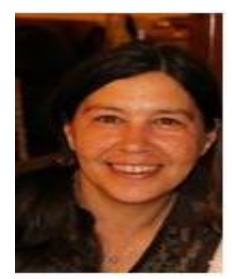

Florinda Martins has a Ph.D. degree in chemical and biological engineering, a master degree in environmental engineering and a degree in chemical engineering from the Faculty of Engineering, University of Porto, Porto, Portugal, obtained in 2007, 1998 and 1989, respectively. She has also worked in industry and nowadays is an adjunct professor at Instituto Superior de Engenharia do Porto (ISEP), School of Engineering, Polytechnic Institute of Porto (IPP), Porto, Portugal. Her research interests include sustainability, environment, energy and optimization.

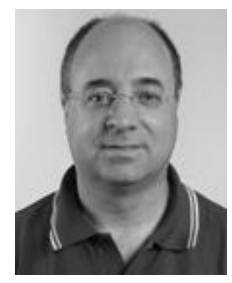

Manuel Carlos Felgueiras received the B.S. and $\mathrm{Ph} . \mathrm{D}$. degrees in electrical and computer engineering from the Faculty of Engineering, University of Porto, Porto, Portugal, in 1987 and 2008, respectively. He started his activity in 1994 as an assistant professor and later as an adjunct professor and researcher with the Department of Electrical Engineering, School of Engineering, Polytechnic Institute of Porto (IPP), Porto, Portugal.

His research interests include design for debug and test of mixed-signals, remote experimentation in e-learning and renewable energy sources.

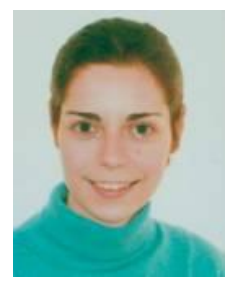

M. Smitková graduated from the Faculty of Mathematics, Physics and Informatics of the Comenius University in Bratislava. In 2009, she received her Ph.D. degree at the Faculty of Electrical Engineering and Informatics of Slovak University of Technology and in 2014. She became an associated professor at Institute of power and applied electrical engineering of FEI SUT. In 2008 she worked via EU project inspire at Enel Research Centre in Italy. Her teaching and scientific activities are focused especially on the topic of renewable energy sources and hydrogen production. 